\title{
Las ideas de Alfred Adler y su asimilación en Paraguay por Guillermo Enciso
}

\author{
José E. García \\ Universidad Católica \\ Asunción, Paraguay
}

Recibido: 11 de julio del 2016 / Aceptado: 20 de enero del 2017 doi: https://doi.org/10.26439/persona2017.n20.1738

Alfred Adler fue el primer disidente en abandonar el núcleo original del psicoanálisis para fundar la psicología del individuo a mediados de la década de 1910. Su enfoque se expandió paulatinamente en muchos países, incluyendo algunos de América Latina, donde los estudios de recepción de las ideas adlerianas han sido poco abundantes, comparados con la tradición freudiana. Los comentarios iniciales sobre Adler en Paraguay datan de 1941 en un artículo de la Revista del Ateneo Paraguayo, escrito por Guillermo Enciso, un abogado y filósofo dedicado a la política y la educación. Enciso incorporó varios principios de la psicología individual que resultaban congruentes con sus intereses en la psicología social y el análisis de la vida colectiva. Este artículo examina la asimilación de las ideas de Adler por parte de Enciso, destacando los conceptos centrales y comparándolos con los posicionamientos del autor paraguayo.

Alfred Adler / Guillermo Enciso / psicología del individuo / historia de la psicología-Paraguay

\section{Alfred Adler's Ideas and their Assimilation in Paraguay by Guillermo Enciso}

Alfred Adler was the first dissident who left the original nucleus of psychoanalysis to establish the psychology of the individual in the mid-1910. This approach expanded gradually in many countries, including some of Latin America, where the studies of reception of the Adlerian ideas are little abundant, compared to those on the Freudian tradition. The initial comments on Adler in Paraguay date back to 1941 in an article of the Journal of Paraguayan Athenaeum, written by Guillermo Enciso, a lawyer and philosopher devoted to politics and education. Enciso used several principles of individual psychology that were consistent with their interests in social psychology and the analysis of the collective life. This article examines the assimilation of Adler's theories by Enciso, highlighting the central concepts and comparing them with the points of view of the Paraguayan author.

Alfred Adler / Guillermo Enciso / individual psychology / history of psychology-Paraguay

Correo electrónico: joseemiliogarcia@hotmail.com 
El psiquiatra austriaco Alfred Adler (1870-1937) ocupa un lugar destacado y, al mismo tiempo, controversial en la historia del psicoanálisis, iniciada por Sigmund Freud (1856-1939), también psiquiatra austriaco, y fundador histórico del movimiento. Como muchos líderes de escuela, Freud había desarrollado su trabajo en una situación de relativo aislamiento, por lo que una de sus preocupaciones esenciales en los comienzos era conseguir una persona lo suficientemente calificada para asumir el liderazgo de la orientación, especialmente tomando en cuenta su creciente proyección internacional a comienzos de la década de 1910. Dos personas habían centrado la expectativa de Freud en este sentido. Además del propio Adler, el otro candidato era el psiquiatra Carl Gustav Jung (1875-1961). Ambos, sin embargo, así como otros más en épocas posteriores, contrariaron las esperanzas de Freud al dejar la casa paterna y carpa ideológica, y lanzarse de lleno en una búsqueda personal de nuevos senderos en la psicología y la psiquiatría. Las reacciones de Freud no fueron suaves ni cordiales ante lo que, en la peculiar terminología psicoanalítica, podría verse como una auténtica herida narcisista, que denotaba manifiestamente su frustración. Los epítetos en contra de Adler, publicados tanto en la Historia del movimiento psicoanalítico (Freud, 1981 [1914]) como en la Autobiografía (Freud, 1981 [1924]), trasuntaban la intolerancia hacia todos aquellos que pudieran considerarse desviados, desleales, infieles, traidores o conspiradores de sus lineamientos teóricos (Sued, 2004), los cuales casi siempre parecían impermeables a la crítica. Decía Freud, en su historia del psicoanálisis, que nada puede impedir marcharse a quienes anhelan deambular por la vida con plena independencia en sus pasos. Pero concluía después con lo que posiblemente expresaba su verdadero sentimiento: que vivir bajo un mismo techo junto a personas con las que no es viable llegar a un entendimiento y a las que simplemente no logramos aguantar, en absoluto resulta un hecho agradable (Freud, 1981 [1914]). Igualmente, Freud (1981 [1924]) opinaba que la defección de Adler, y más tarde la de Jung, no debía la fuerza de su impulso al contenido propio de las doctrinas, sino al deseo de emanciparse de ciertos resultados del psicoanálisis, incluso aceptando implícitamente los datos en que se basaban, aunque discordando en la interpretación. La partida de Adler desde el círculo más cercano y estrecho del creador del psicoanálisis, y convertido luego en alguien con criterio propio e independiente, no parecía haber sido lamentada por Freud, sino incluso bienvenida. El primer disidente, a partir de entonces, comenzaría a hacer sus propias armas.

Sin embargo, describir a Adler como un simple alumno o pupilo no refleja cabalmente la naturaleza exacta de la relación que ambos mantuvieron. Él fue uno de los fundadores en 1902 de la Sociedad Psicológica de los Miércoles, que posteriormente, en 1908, se transformaría en la Asociación Psicoanalítica Vienesa. Cordón (2012) lo considera un pensador original y arguye que la invitación a participar en las discusiones de estos grupos fue en carácter de colega de Freud, no de mero discípulo. El abandono 
de Adler del entorno freudiano lo puso ante la gran responsabilidad de caminar apoyado en sus propias fuerzas $\mathrm{y}$ recursos. Y lo más importante: ante el compromiso de enmendar en una teoría nueva lo que había percibido como los errores, exageraciones, desaciertos y sinsentidos del psicoanálisis originario. Ciertamente, lo hizo con satisfactorio éxito. Además, la salida de Adler no fue un hecho individual, sino que se llevó consigo a nueve miembros de la asociación, incluyendo a la única mujer que la integraba (Buschiazzo, 2012). En los años que siguieron, desarrolló una propuesta teórica distinta y novedosa que ganó un lugar propio en la psicología. Más adelante, también afrontaría sus propias fugas, como la del psiquiatra vienés Rudolf Allers (1883-1963), un agudo crítico del psicoanálisis en su modalidad freudiana (Allers, 1940), que en 1927 partió de las filas adlerianas para instituir su propia orientación en el humanismo psicológico (García-Alandete, 2015). La aproximación de Adler ha llegado a conocerse como la psicología del individuo o psicología individual, y constituye un recuento de todo cuanto concierne a la persona y la sociedad, así como sus relaciones mutuas (Ganz, 2001 [1953]). No obstante, hay otros aspectos en su enfoque que podrían no ser evidentes, aunque sí muy relevantes. El conjunto de ideas y teorías que planteó fue lo suficientemente dúctil y elástico para que se lo reconozca, en ocasiones, como un neopsicoanalista y en otras, inclusive, como un autor cercano a los parámetros de una psicología de corte más existencial. Algo así no ocurre de ordinario con cualquier referente histórico. Bien sabida es la tendencia de encasillar a los autores en categorías teoréticas compactas o "escuelas", a veces con un simplismo desmedido, y con el único objetivo de evaluar su mayor o menor congruencia en virtud de los supuestos de las mismas. Con Adler, esto no puede realizarse con facilidad. Por lo tanto, incluso esta dimensión de su trabajo le confiere un atractivo adicional.

Adler cosechó numerosos seguidores en distintos países, pero en otros su impacto fue considerablemente menor o, en todo caso, relativamente tangencial. En nuestro continente, su influencia se ha visto muy opacada por la inserción arrolladora que experimentó el psicoanálisis freudiano, sobre todo en países como Argentina y Uruguay. Igual suerte corrieron otras líneas emparentadas o derivadas de él. En 1920, el psiquiatra peruano Honorio Delgado (1892-1969) comentó una obra central de Adler, El carácter neurótico, en la Revista de Psiquiatría y Disciplinas Conexas, y aludió a otros trabajos en escritos diferentes (León y Zambrano Mora, 1992). En Argentina, el médico Jorge Thénon (1901-1985) escribió en 1928 sobre el valor de la psicoterapia para la medicina práctica y estableció entre sus principales aproximaciones al psicoanálisis $\mathrm{y}$ algunos de sus derivados, como la psicología del individuo (Falcone, 2007). Otro referente importante es Jaime Bernstein (1917-1988), quien publicó algunos volúmenes introductorios al pensamiento de Adler, así como estudios muy detallados a las primeras traducciones que se 
hicieron a la lengua castellana (Bernstein, 1965). En otras partes del continente, como Guatemala, hubo psiquiatras como Carlos Mora Portillo (1889-1972) que tuvieron la oportunidad de asistir a seminarios dictados por Adler en Europa, así como por Freud y Jung (Von Ahn, 1996), y acusan una perceptible influencia. Pero, en general, la información concerniente a la asimilación del autor vienés es llamativamente escasa, o muy dispersa e incidental. En un sentido relacionado, los intereses de psicólogos europeos con simpatías adlerianas respecto a la producción psicológica latinoamericana, concebida en forma amplia, se constatan en la publicación de reseñas de libros y revistas, pero muy escasamente como instancias colaborativas, que pudieran haber llevado a una propagación de los conceptos de Adler con la misma intensidad y penetración que se dio para los constructos freudianos. En este sentido, León (2000) estudió la presencia de psicólogos de nuestro continente en las páginas de la Internationale Zeitschrift fuer Individualpsychologie (Revista Internacional de Psicología Individual), encontrando que la mayor parte de las menciones se deben a autores como Max Cresta y Lydia Sicher. Ellos comentaron, particularmente esta última, las obras de exponentes de la psicología latinoamericana a lo largo de varios años consecutivos, desde una perspectiva afín a la psicología del individuo.

Sin embargo, Adler es una figura muy poco mencionada y peor conocida en Paraguay, tanto en el periodo preuniversitario, es decir, la etapa que se identifica con la difusión de la psicología antes que esta fuera establecida en cuanto opción universitaria formal (García, 2005b), como en la fase que arranca en la década de 1960 con la fundación de los primeros departamentos académicos. Todavía hoy, muchos de los que egresan de las carreras de psicología saben muy poco o casi nada sobre él. Con la obra de Freud, en contraste, no sucedió lo mismo. El primer ensayo que difundió los conceptos freudianos, aunque no haya conducido hacia nada semejante a una práctica incipiente de la terapia psicodinámica, sino únicamente a una divulgación teórica, se registró en 1927 por parte de un educador, Ramón Indalecio Cardozo (1876-1943) (García, 2003b), en un artículo publicado en una revista pedagógica nacional (Cardozo, 1927). Para mediados de la década de 1940, no obstante, algunos psiquiatras habían comenzado sus estudios con la finalidad de iniciar la práctica de la terapia psicoanalítica con una dirección profesional (García, 2011). Una vez instituidas las primeras carreras universitarias en la década de 1960, la llamada psicología profunda se convirtió en una de las orientaciones teóricas más importantes, y la dominante si hemos de atenernos específicamente a los decenios de 1960 y 1970. Pero no es sencillo encontrar referencias escritas que discutan o popularicen los constructos de Adler, y más improbable aún es hallar exponentes de aplicaciones clínicas alineadas con esa perspectiva. En este artículo, queremos hacer referencia a una de esas excepciones que revisten el carácter de antecedente histórico fundamental: 
la de un autor nacional, Guillermo Enciso, que realizó una exposición crítica de Adler por primera vez en el contexto de la psicología paraguaya. En relación con ese tema, los objetivos que guían este trabajo son los siguientes: (a) estudiar la representación del enfoque de Alfred Adler a partir de los escritos del autor paraguayo Guillermo Enciso; (b) indagar sobre la asimilación de las teorías adlerianas, en especial la interpretación y trasposición que de ellas produjo Enciso; (c) analizar las críticas que dirigió Enciso hacia otros autores colaterales, como Sigmund Freud y Gustave Le Bon, surgidas en su discusión de Adler; y (d) evaluar la significación de este trabajo en el panorama histórico amplio que corresponde a la psicología paraguaya. Para acometer estos propósitos, haremos uso de las fuentes primarias de Enciso y algunas de Adler, estableciendo la interdependencia que hila al escritor paraguayo con el autor austriaco. Como marco general, presentaremos a continuación el contexto general de las ideas de Adler y lo que tienen de singular para su psicología.

\section{LA PSICOLOGÍA INDIVIDUAL}

Alfred Adler, de ascendencia húngara, nació en un hogar suburbano de Viena. $\mathrm{Su}$ padre era un acaudalado comerciante judío de granos. En su niñez, sufrió de varios trastornos de salud, como raquitismo y neumonía, lo cual influyó muy fuertemente en su autoestima, pero también en su firme determinación de estudiar medicina (Lawson, Graham y Baker, 2016). Tras la graduación en la Universidad de
Viena en 1895, su vocación se dirigió hacia la oftalmología. Pero más tarde sería uno de los primeros en acercarse y demostrar interés en las teorías de Freud, con quien mantuvo colaboraciones personales durante algunos años, aunque demostrando una respetable independencia de criterio. Su primer contacto con el psicoanálisis fue a través de una lectura de La interpretación de los sueños (Hergenhahn y Henley, 2013), obra que Freud puso en circulación a comienzos del siglo xx (Freud, 1981 [1900]). A partir de ese momento, y particularmente desde su encuentro personal en 1902 hasta el cisma de 1911, las relaciones entre ambos fueron de cooperación mutua. Como antes mencionáramos, Adler fue no solo un miembro destacado, sino incluso presidente de la Sociedad Psicoanalítica de Viena en 1910. Poco a poco, las discrepancias comenzaron a surgir, lo que finalmente condujo a la inevitable ruptura. No obstante, cuando los vínculos con el padre del psicoanálisis aún eran armónicos, Adler ya daba muestras de sus iniciativas teóricas autónomas. En 1907, elaboró su explicación de la inferioridad orgánica, partiendo de un análisis de las patologías renales. Creía que los seres humanos padecemos del sentimiento de inferioridad originado en el mal funcionamiento de un órgano o grupo de órganos, lo cual tratamos de compensar en formas psicológicamente efectivas (Adler, 1917a). Muchas personas tienden a utilizar sus problemas físicos para resolver dificultades que se generan en otros ámbitos de la vida. Estas suposiciones fueron el germen de la posterior teoría sobre los complejos de superioridad e inferioridad 
(Weckowicz y Liebel-Weckowicz, 1990). Stepansky (2012) considera, además, muy importante este trabajo por otro detalle adicional: constituyó la transición real de Adler desde el ámbito general de la medicina al más delimitado de la psiquiatría.

Las ideas de Adler provenían de un conjunto muy variado de fuentes, incluyendo sus intereses tempranos por la justicia social, su cruce temporal por el marxismo, la práctica de la medicina y las relaciones con Freud, así como la lectura y discusión de los filósofos Immanuel Kant (1724-1804), Friedrich Nietzsche (1844-1900) y Arthur Schopenhauer (1788-1860) (Angioli y Kruger, 2015). Lo esencial de esta construcción psicológica se produjo entre 1902 y 1916, periodo en el que se habían conformado ya las líneas de su pensamiento básico, una parte del cual coincidió con su adscripción originaria al freudismo. Esa vinculación con el movimiento psicoanalítico, sin embargo, también encontró consecuencias negativas. Por ejemplo, en 1912, cuando la ruptura con Freud ya era un hecho consumado, Adler intentó ganar una posición como profesor en la Universidad de Viena y cursó la solicitud correspondiente a las autoridades académicas, pero fue rechazada en 1915 después que una comisión conformada para su estudio emitiera un dictamen negativo, basada en el supuesto, ya erróneo en ese momento, de que Adler compartía los postulados del psicoanálisis. Sus evaluadores cuestionaron enfáticamente la suposición sobre la vigencia ilimitada de la sexualidad, punto de vista muy discordante con el de los profesores vieneses, que se adherían a una concepción más positivista de la medicina (Lück, 2004). Con tan adverso panorama, Adler quedó definitivamente excluido de la docencia terciaria, y perdió la inigualable oportunidad de irradiar su mensaje entre los muros de la academia.

El supuesto de que los seres humanos se hallan motivados a buscar la igualdad o la superioridad sobre otros, con el fin de compensar lo que en su infancia pudo haberse vivido como un signo de debilidad, se mantuvo en los años subsiguientes. Una forma es el deseo del adulto por volverse poderoso, subsanando la sensación de inferioridad en su etapa de niño. Esta clase de sobrecompensación se denomina protesta masculina y puede darse también en las mujeres, aunque es particularmente frecuente en los hombres, sobre todo en los de menor edad. Algunos individuos del sexo masculino, en su juventud, desarrollan este anhelo particular por demostrar su control, supremacía, autoridad y masculinidad. Tal condición precisa exteriorizarse a través de acciones concretas que evidencien el dominio sobre los demás, y no ser percibidas simplemente como una experiencia subjetiva. Por estos motivos, la protesta masculina es una consecuencia de los sentimientos arraigados de inferioridad (Funder, 2013). Cuanto más agudo sea el convencimiento, mayor será la necesidad de compensarlo de maneras que, a la larga, producirán trastornos emocionales y una conducta autodestructiva. Dumont (2010) observa que esta suerte de voluntad de poder nietzscheana no desemboca en su búsqueda como un fin en sí mismo, sino en la necesidad de 
mantener la integridad personal en un contexto social específico, donde no se excluye la competencia. Se expresa en conglomerados de comportamientos que Adler llamó estilos de vida. Con ellos se conectan directamente los complejos de superioridad e inferioridad.

En sus comienzos, la psicología individual se denominó psicoanálisis libre, al menos por un breve periodo. Los puntos de divergencia con el psicoanálisis oficial se hicieron muy patentes en torno a asuntos críticos, como los fundamentos sexuales de las neurosis. Adler (1917b) mencionó que dicha cuestión le parecía tan errónea que amenazaba incluso con obstaculizar la verdadera comprensión de los procesos. La primera y más importante objeción era que la libido constituye la fuerza motivadora que subyace a la producción de los eventos neuróticos; la segunda, que estas obedecían a una etiología sexual; y la tercera, la suposición de que el sujeto que las padece se halla bajo la influencia de algunos deseos infantiles, que vuelven a la vida en el sigilo de la nocturnidad, así como en conexión con ciertos acontecimientos de la vida. Queda claro que uno de los aspectos más evidentes en el alejamiento de Adler de la ortodoxia freudiana fue la interpretación divergente sobre estos fenómenos. En la conceptualización adleriana, la persona que sufre esos males se va alejando gradualmente de la realización de sus tareas cotidianas, y con ello evita la pérdida de su autoestima, que resulta de las interpretaciones personales de fracaso (Abramson, 2015). Esta situación se fundamenta en una combinación de los sentimientos de inferioridad y el esfuerzo por demostrar la superioridad. La permanente retracción de las actividades vitales conduce a un pobre desarrollo de los intereses sociales, y habitualmente se conecta con una historia de sobreprotección infantil. Para resguardarse a sí mismos, quienes soportan el asedio de la neurosis deben crear toda suerte de excusas o síntomas.

Por lo tanto, cada persona, cada destino singular, solo puede ser cabalmente comprendida si se toman en cuenta las condiciones irrepetibles que son propias de cada quien (Adler, 1948). Esta es la forma, igualmente, en que una psicología del individuo habrá de conducir hacia una ciencia del vivir. El modelo concebía las existencias particulares en su totalidad y estimaba que cada reacción simple, cada movimiento e impulso constituían una parte articulada con la actitud individual hacia los eventos circundantes de la vida. Adler (1930) remarcaba que su enfoque había crecido a partir de los esfuerzos por comprender ese impulso creativo que se expresa en el deseo por desarrollarse, de luchar y de compensar las derrotas sufridas en una esfera determinada de la vida, consiguiendo el éxito en otras. Este poder se reconoce en el empeño por acceder a las metas apetecidas. En esencia, Adler se alejó de una concepción esencialmente patológica de las experiencias humanas para acercarse a un punto de vista más concordante con el predominio de la normalidad. Así debe comprendérselo, por ejemplo, cuando afirma:

En nuestras investigaciones hubimos pronto de reconocer que aquellas anomalías, complicaciones y errores anímicos, 
que tan frecuentemente se echan de ver en casos de enfermedad, no contenían en el fondo por su estructura nada que fuera ajeno a la vida del alma del llamado hombre normal. (Adler, 1947, p. 13)

Para la psicología individual, los seres humanos están orientados hacia la consecución de metas vitales. A esto se refería Mira y López (1963), en su punto de vista clásico, al sostener que una de las diferencias esenciales con el enfoque psicoanalítico tradicional es que Adler se proyectó más hacia el porvenir individual que Freud, interesándose por saber hacia dónde se dirigía la persona en lugar del origen remoto para sus problemas. En clara oposición, la psicología adleriana sostuvo que el individuo se encamina hacia sus objetos de interés y los fines que le atraen en una forma propositiva. Ellos son puestos por el propio sujeto, muchas veces incluso sin su deliberación consciente. Las personas no son vistas como entes movidos por las fuerzas ciegas $y$ deterministas de su pasado, sino atraídas por el futuro, en gran medida creado por ellas mismas (Brett, 1997 [1927]). Resulta evidente que las discordancias con el psicoanálisis clásico desbordaron el ámbito estricto de la psicología, para convertirse en agudos contrapuntos metapsicológicos (Mora Mérida y Laza, 1986). La aspiración por conseguir objetivos también demuestra por qué esta psicología es eminentemente social. Adler (1953) afirmaba que el conocimiento del hombre solo puede lograrse en la medida en que se comprenda su posición ante los deberes que emergen de la comunidad. La actividad social que cada uno libra demuestra su adhesión a las exigencias reales que impone la vida colectiva. El individuo, por consiguiente, surge de la peculiar mezcla de los sentimientos de sus coetáneos y la tendencia hacia el logro de su posición de superioridad.

Estas formulaciones teóricas ayudan a comprender por qué Adler, mientras es conceptuado como integrante de una orientación psicodinámica de segunda generación, también es visto como un antecesor de los modelos humanistas (Obuchowski, 1988), donde resaltan Carl Rogers (1902-1987), Rollo May (19091994), Abraham Maslow (1908-1970) y Viktor Frankl(1905-1997). A este respecto, Chávez (2009) apunta que las diferencias ideológicas entre Adler y Frankl, si bien indudablemente existen, son menores de lo que habitualmente se supone, e incluso podrían ser complementarios. Alarco von Perfall (2015) indica que el verdadero origen de la psicología humanista radica en la psicología individual de Adler, y que sus influencias se extienden incluso hasta la moderna psicología positiva. Las convergencias parecen por demás evidentes cuando Adler afirma que son tres los principales problemas que puede plantearse todo ser humano: (a) la actitud frente al prójimo, (b) la profesión y (c) el amor, y que ellos, además, se hallan lejos de resultar causales, pues se encuentran insertos de manera inexorable en el destino del hombre. Por tales motivos, la psicología individual es un modelo muy elusivo a las clasificaciones definitivas, y con una cierta ductilidad para fusionarse a otros puntos de vista no enteramente coincidentes. Esta es la razón principal por la 
que personas con intereses diversos han podido identificarse productivamente con algunos de sus postulados. Un ejemplo lo brinda la asimilación inicial de Adler en Paraguay, que se produce a través de un escritor con vinculaciones a la vida práctica y la política, como Guillermo Enciso. En las páginas que siguen, analizaremos la circunstancia histórica y el perfil de figura pública que corresponde a este autor y el modo como él representó la posición de Adler.

\section{Pinceladas BIOGRÁficas de Guillermo Enciso}

Ypané es una pequeña localidad que tuvo su origen como reducción franciscana en 1538 y se encuentra a 27 kilómetros de la ciudad de Asunción. Allí nació Guillermo Enciso el 6 de septiembre de 1899. Fue un alumno muy aplicado y se destacó obteniendo una medalla de oro por sus logros académicos. Terminados sus estudios secundarios, viajó a España para desarrollar su entrenamiento universitario en las áreas de derecho $\mathrm{y}$ filosofía, en la Universidad de Madrid, en 1926 (Centurión, 1961). Recibió sus diplomas de manos del rey Alfonso XIII y retornó al país en 1929. Desde entonces, ocupó cargos públicos de relevancia en el área educativa, como el de director general de Escuelas. Combatió en la guerra del Chaco, que enfrentó militarmente a Paraguay con Bolivia entre 1932 y 1935. Ejerció el periodismo durante muchos años y tuvo participación como articulista o director en varias revistas y periódicos como Guarania, Cultura, El País y Patria, esta última fundada por Enciso y que fuera el diario oficial del Partido Colorado (Prieto Yegros, 1985). Guarania no era solo una revista cultural; su director también utilizó los editoriales para reivindicar la disidencia de la revista, y la suya por añadidura, respecto a las ideas políticas del líder fascista italiano Benito Mussolini (1883-1945) en la década de 1930. Reafirmó que la doctrina del Partido Colorado, en el que militaba Enciso, difería de aquel en cuestiones tan esenciales como la concepción del Estado (Seiferheld, 1985). En un plano más afín a nuestros intereses, su vinculación con la psicología se produjo a través de la actividad docente en colegios públicos, donde impartía clases de psicología infantil en el cuarto curso de la enseñanza media (República del Paraguay, 1945). También a través de sus escritos, como pronto veremos.

La trayectoria de Enciso en la instrucción pública le valió el nombramiento como ministro de Educación en 1946 (López, 2014), durante la presidencia del general Higinio Morínigo (1897-1983). Este había promovido ese mismo año un experimento de apertura política, poco habitual en lo tumultuoso de la historia paraguaya, caracterizada por los regímenes autoritarios. El ensayo fue conocido como la primavera democrática y tuvo vigencia durante los meses previos al estallido de la revolución de 1947, pero solo se mantuvo por el breve lapso de seis meses. En aquel gobierno participaron referentes del Partido Colorado, el Partido Revolucionario Febrerista y representantes de la cúpula castrense. En los hechos, era una formación cívicomilitar. Las condiciones del país en enero 
de 1947 y el presumible riesgo de un golpe de Estado a causa de la inestabilidad predominante llevaron al presidente Morínigo a discutir con los altos mandos del Ejército la posibilidad de establecer una administración exclusivamente militar o convocar al Partido Colorado para una gestión compartida, con la inconfesa pretensión de desplazar a los febreristas de la estructura gubernamental. Se orquestó entonces un complot que acabaría entronando al Partido Colorado como el brazo civil del poder. Entre los actores principales que urdieron esa suerte de asalto palaciego, que tuvo lugar el 13 de enero de 1947, se encontraba Guillermo Enciso. Aunque formalmente los febreristas se alejaron de forma voluntaria, el resentimiento que sobrevino tuvo un alto costo. Ellos iniciaron las principales acciones políticas que finalmente desencadenaron la revolución el 8 de marzo de 1947, en la norteña ciudad de Concepción (González Delvalle, 2007).

El peso de Enciso como un actor político influyente se percibe en el hecho de que, en los acercamientos estratégicos de Estados Unidos hacia Morínigo, que comenzaron a insinuarse claramente a partir de 1943, él fue uno de los paraguayos ligados al ámbito de las ciencias sociales que recibió invitaciones financiadas para dictar conferencias en universidades norteamericanas e involucrarse directamente en proyectos de investigación, cuando las circunstancias lo permitiesen (Mora y Cooney, 2009). La administración estadounidense desplegó crecientes esfuerzos por neutralizar las abiertas simpatías de algunos integrantes del gabinete nacional hacia las Potencias del Eje y sus aliados. Fruto de esos contactos con los políticos de Washington, devino su nombramiento como embajador ante el Gobierno de Estados Unidos, la Organización de las Naciones Unidas (ONU) y la Organización de Estados Americanos (OEA), en 1947. A su retorno al país, continuó ejerciendo cargos en los sucesivos regímenes colorados y ocupó la cartera de ministro de Justicia y Trabajo con el presidente Federico Chávez (18821978), quien resultara electo en 1950 por un periodo de tres años, y obtuviera una reelección en 1953. Él estableció un plan de estabilización y fomento para el fortalecimiento económico y la reconstrucción nacional, como paso previo a la restitución completa de las libertades civiles, uno de cuyos impulsores fundamentales era Enciso (Scavone Yegros, 2011). Pero habrían de separarlo de su cargo a comienzos de 1954. Como resultado de una serie de errores políticos y riesgos mal calculados, Chávez fue depuesto por Alfredo Stroessner (19122006) en un golpe de Estado en mayo del mismo año. Ese evento inició una de las etapas más fatídicas y oscurantistas en la historia paraguaya reciente.

Para entender mejor los entretelones que explican la separación de Enciso en el gabinete de Chávez, hay que recordar su intervención activa en algunos eventos relacionados con la organización obrera internacional, que alcanzaron un punto álgido a nivel regional con la celebración de la Primera Conferencia Sindical del Río de la Plata, albergada en Asunción en febrero de 1952 por invitación 
de la Confederación Paraguaya de Trabajadores (CPT). Este encuentro, que mantenía afinidades doctrinarias con el Partido Peronista argentino, buscaba, al menos en los papeles, una postura no alineada y equidistante tanto del capitalismo como del comunismo. Enciso fue uno de los oradores que habló en la sesión de apertura de las deliberaciones (Alexander y Parker, 2009). Precisamente, esta aproximación muy marcada y perceptible hacia el peronismo habría de originar un creciente malestar en los sectores nacionalistas del Ejército, que hicieron llegar sus quejas al presidente Chávez a comienzos de 1954, sugiriendo además que Enciso conspiraba activamente contra el Ejecutivo (Caeiro y Flecha, 2001). Era una acusación que no carecía completamente de lógica, como demuestra el hecho posterior de que Enciso presidiera una comisión al interior del Partido Colorado que postulaba la candidatura de Stroessner (Escobar Martínez, 1978), uno de los pasos previos del futuro dictador para sus intentos de legitimación como gobernante. Como puede apreciarse, la trayectoria de Enciso no estuvo exenta de aspectos políticamente controversiales. Su militancia activa en las filas del oficialista Partido Colorado le llevó a ocupar incluso la presidencia del mismo. Pero la personalidad y actividad pública de este ciudadano, aunque visiblemente ligada al ámbito político y diplomático, fue como una amalgama muy dinámica entre las aspiraciones que imponen la vida colectiva y sus inclinaciones personales de síntesis intelectual. Allí radica su perfil más interesante. Como escribiera el también activista colorado Epifanio Méndez
Fleytas (1917-1985), Enciso fue "la paradoja viviente entre la apariencia de su acritud y la delicadeza exquisita de su sensibilidad" (Méndez Fleytas, 1979, p. 132). Falleció en 1963.

\section{LOS PELDAÑOS QUE CONDUCEN}

\section{a Adler: Freud, Jung y Le Bon}

Guillermo Enciso es una de las figuras menos conocidas en lo que se refiere a sus relaciones particulares con la psicología paraguaya y su evolución histórica. Un escrito de su autoría, titulado "Ensayo de interpretación psicológica de lo social" (Enciso, 1941), fue difundido en las páginas de una revista cultural a comienzos de la década de 1940. En algunos trabajos anteriores, se identifica a esta contribución como una de las que integra la naciente literatura paraguaya en psicología social durante la primera mitad del siglo xx (García, 2003a). Mención única, forzoso es decirlo, en todo el contexto documental que concierne a la historiografía de la psicología en este país. Sin embargo, es un artículo con valor propio, que no cabe ignorar, pues posee ribetes de originalidad para lo que significa el proceso de formación de la psicología a nivel local, por lo que una mayor profundización y conocimiento de su contenido queda plenamente justificado. El ensayo, cuya extensión es de solo once páginas, apareció en el número del primer trimestre de 1941 en la Revista del Ateneo Paraguayo. Esta publicación es una pieza muy importante en la producción intelectual paraguaya, pues, aunque sufrió discontinuidades en muchas ocasiones, 
tuvo varios renacimientos en los que siempre reflejó una amplia gama de intereses temáticos, que van desde la poesía y la prosa hasta la ciencia. En su periodo moderno, se la considera una continuidad de la célebre Revista del Instituto Paraguayo, de similares características y editada entre 1896 y 1909 como órgano del desaparecido instituto homónimo, y sobre cuya importancia singular para la psicología preuniversitaria en Paraguay se dispone de un estudio pormenorizado (García, 2014).

Bajo el epígrafe de "Advertencias previas", Enciso comenzaba su argumentación indicando que su meta no es plantear, y menos aún resolver, los problemas generales que esboza la psicología colectiva. En Paraguay, quien primero discutió las relaciones de la psicología individual con la psicología social y la psicología colectiva fue Ignacio A. Pane (1880-1920), en sus Apuntes de sociología (1917). Esclareciendo sus objetivos, Enciso advierte que no es su propósito argumentar con una finalidad moralizante o política. Cree que la psicología social debería fundarse en la psicología individual, aunque aquella no puede albergar pretensiones mayores, ya que, por el momento, solo constituía una buena intención científica. Se asume, entonces, que tanto la psicología social como la individual, que es el foco de atención para el artículo, son emprendimientos intelectuales que se hallan en pleno desarrollo. Cualquier interrogante que pudiese surgir en cuanto a las motivaciones por las que un hombre de raigambre política como Enciso estuviera involucrado en la discusión de cuestiones de talante psicológico, encuentra una respuesta inequívoca en sus expresiones iniciales, que pone los bueyes de la necesidad de relevancia práctica por delante de la pesada carreta teórica. Y que, además, deja muy claro el sentido para este interés:

$\mathrm{Si}$ intentamos este esbozo de interpretación psicológica de lo social, lo hacemos con el propósito de interesar a la clase intelectual paraguaya a dedicar su atención a una cuestión de relevancia cultural y político-social, aparte o por encima de su importancia estrictamente científica. (Enciso, 1941, p. 35)

El problema básico al que hacía referencia era el de la voluntad de dominio, un tópico inserto en la agenda temática de la psicología social. Se refería al factor, principio, fuerza, propensión o compulsión primordial que es el principal responsable tanto de la conducta individual como de la integración de las sociedades en sí mismas. También guardaba conexiones con el ámbito de las ideas, los sentimientos y la acción humanos. La voluntad de dominio podía conceptualizarse en formas muy variadas, por lo que designaciones alternativas como el instinto de poder, el afán de superioridad, el anhelo de preeminencia, el ansia de hacerse valer o la tendencia a la expansión resultaban equivalentes. A Enciso (1941) le preocupó que las intenciones de su artículo fueran malinterpretadas, concibiéndolas como una simple exaltación de la potencia bruta que favorecía la imposición efectiva de unos seres humanos sobre otros. Recuerda el sentido que esta postulación de la 
voluntad de poder adquirió en Friedrich Nietzsche (1844-1900), uno de los referentes intelectuales más conocidos entre los que sustentaron aquel concepto en el tiempo moderno, así como en su oposición a la prédica de su contemporáneo Arthur Schopenhauer (1788-1860), en lo atinente a la tenacidad por vivir. Pero era ineludible percibir las cosas con mayor amplitud. La preponderancia y la dominación no involucran solamente la dimensión física ni el avasallamiento. Había que situarlos en una perspectiva más amplia que no excluyese la supremacía física, pero que también abarcara manifestaciones tales como el vigor de la santidad, y se desplazara a partir del egoísmo particular hasta la identificación del Yo con el conjunto del bienestar social. En este contexto, el autor recoge su primera alusión específica a las construcciones teóricas de Adler, cuyo concepto del sentimiento de la comunidad es, para Enciso (1941), una forma en la que también se revela el instinto del poder.

La mirada de Enciso estaba puesta en las doctrinas de Adler, aunque, para subrayar con claridad la orientación singular de su pensamiento, tomó la precaución de despejar incógnitas, primero en alusión a los preceptos del psicólogo social francés Gustave Le Bon (1841-1931), y segundo con referencia a Sigmund Freud (18561939), creador del psicoanálisis y hacia quien manifestó reservas fundamentales, con el propósito de diferenciar nítidamente su concepción. En el escrito, por ejemplo, se propuso analizar "sus direcciones o desviaciones principales" (Enciso, 1941, p. 36). Asimismo, destacó el perfil de Adler como médico y educador, de reciente desaparición al momento de escribir el artículo. No obstante lo cual, advierte que se aparta de él en determinados aspectos de su pensamiento, de modo que no cabe esperar una simple relación de adherencia dogmática. Este es un detalle muy importante para entender de qué forma Enciso asimiló a Adler. Tras someter a repaso los principios básicos de Le Bon y Freud, se detenía en una discusión de las premisas adlerianas, enfatizando la articulación de su propia visión personal con las mismas. Esta clase de reflexiones lo perfilaban, en sus propias palabras, como un seudoadleriano. Además, Enciso (1941) creía que la denominada psicología sintética -que infortunadamente no definehabía logrado integrar todos los elementos que aparecían dispersos en el estudio de la mente humana. Ella recibía una contribución fundamental del psicoanálisis, cuyo argumento central era, como es sabido, que todas las actividades psíquicas se hallaban determinadas por el nivel inconsciente o lo "psíquico pretérito". Por su parte, Enciso (1941) señaló su acuerdo parcial con lo esencial de esta posición. Las acciones que se derivan de las huellas mnémicas o la memoria, así como las arremetidas impetuosas que provienen de los instintos, aunque parezcan elementos en apariencia desechados u olvidados, anónimos integrantes de la arquitectura mental, seguían ejerciendo una acción continua y determinante.

Tres son los itinerarios principales que se reconocen en el trayecto del psicoanálisis y sus derivados intelectuales. (a) La versión original de Freud, centrada en el concepto medular de la libido sexual, 
que se estima como el factor primordial que genera todo el conjunto de la vida psíquica. Esto le ha valido el calificativo de pansexualista, que Enciso admite sin reservas, puntualizando, además, su carácter causal. (b) La orientación que corresponde a la psicología individual de Alfred Adler, cuya proposición básica es el afán de hacerse valer y el ansia de superioridad. La perspectiva es de carácter finalista y, al mismo tiempo, optimista. (c) La línea iniciada por el otro gran discrepante con la ortodoxia freudiana, Carl Jung, que constituye el prototipo de un acercamiento más místico. Tras iniciar su trabajo con la enunciación del inconsciente colectivo, Jung se encaminó hacia lo que Enciso (1941) calificaría como una metapsicología religiosa. De los tres, Adler es el que más sobresalió por sus incursiones educacionales. Y, aunque estos modelos comenzaron con un discurso centrado en la psicología individual y terapéutica, los intereses de los tres desbordaron pronto hacia la interpretación de los hechos psíquicos sociales. En el caso de Freud, este ámbito quedó centralizado en Psicología de las masas y análisis del yo (Freud, 1981 [1921]), su obra cardinal en este terreno; en Jung, con el constructo fundamental del inconsciente colectivo, fuertemente evocador de la mentalidad atávica; y en Adler, en la afirmación del sentimiento de comunidad, que emerge a lo largo del desarrollo infantil como contrapunto entre el imperativo de la individualidad y las exigencias que impone el entorno social, todo lo cual se halla en la base de los procesos psicológicos humanos.
Las ideas de Le Bon son importantes, no solo por el valor que poseen en sí mismas, sino por lo que tuvieron de influyentes en la génesis de las concepciones sociales que abrazó el freudismo. El autor de La psicología de las multitudes (Le Bon, 1895), más pensador que investigador en la percepción que de él tuvo Enciso (1941), había sostenido que los actos conscientes derivan de un sustrato inconsciente, donde se hallan enterrados los remanentes de la mentalidad ancestral. En estas palabras, se reconoce tanto a Freud como a Jung, y constituyen una antecedencia innegable para sus respectivos sistemas. En los contextos apropiados, donde la individualidad se difumina, protegida en el anonimato que permiten los agrupamientos numerosos y que da lugar a la liberación de los instintos, las aglomeraciones o las masas consiguen levantar el bloqueo a estos patrimonios del primitivismo arcaico. Le Bon (1895) pregonaba que en el gentío los sujetos aislados se transforman radicalmente por efecto de tres factores esenciales y concomitantes: (a) el número, (b) el efecto que produce el contagio y (c) la sugestibilidad. La turba, que desencadena efectos muy similares a los del ensoñamiento hipnótico, se caracteriza por liberar el inconsciente de sus férreas ataduras y retrotraer al individuo hacia estadios de civilización primitivos. En el alma de las multitudes, Le Bon descubre el carácter impulsivo e irritable de la misma, su talante esencialmente irracional, y la plena voluntad que tienen las personas de someterse al dominio pasivo de un jefe o cabecilla, a quien obsequian su autonomía; así se logra esa fidelidad 
que solo se consigue al costo de aprisionar la adhesión de la muchedumbre y arrastrarla tras los designios del líder.

Esta concepción, sin embargo, obtuvo significativos reparos por parte de Enciso. Cuestionó, por ejemplo, que la visión del autor francés se fundamentara casi exclusivamente en los eventos colectivos que tuvieron lugar durante la Revolución francesa, con lo cual dejaba sin analizar — pese a la opinión contraria de Le Bon- la dinámica de los grupos sociales que se encuentran permanentemente movilizados. No logra esclarecer satisfactoriamente las causas que conducen a la formación de tales agregados humanos, ni el surgimiento de los líderes mesiánicos, ni la necesidad de obediencia de que hacen gala las multitudes. Estos son procesos que a la vez requieren ser explicados de alguna manera convincente, pues son resultado de algún factor menos visible, y no simples incitadores de acciones. Además, Enciso desconfía de la actitud de Le Bon, a la que considera tributaria de una sesgada presunción racionalista, que reacciona espantada y temerosa a la expresión muy primaria de quienes se alzan contra sus opresores circunstanciales. Freud tuvo sus propios conceptos sobre este problema. Independientemente de qué tipo de multitud se trate, reconocía en ellas el predominio de la emotividad y el sojuzgamiento del intelecto. En esto, las semejanzas de Freud con Le Bon son bastante evidentes. Pero el psicoanálisis también consideró que los fenómenos que se desencadenan cuando entra en acción la fuerza arrolladora de la turba, cuya acción puede obedecer a la imitación, no se explican solos, sino que responden a causalidades diversas. Para Freud, la respuesta está en la presión omnipresente que ejerce la libido, impulsando la formación dinámica de las masas. La cohesión en que se mantienen estos grupos obedece a su influjo directo. Por eso, es el impulso sexual el componente que los une en última instancia, ya sea en la hermandad de las iglesias ante el amor de Dios Padre, o en la camaradería que se origina entre los soldados de un ejército, que permanecen leales al mando único del superior. Tales elementos se hallan en el cimiento absoluto de toda la psicología social humana.

\section{Una perspectiva local sobre Adler}

A los análisis de Le Bon y Freud, el primero sometido, como vimos, a una crítica explícita, Enciso confrontó sus propias opiniones sobre los vínculos entre el comportamiento individual y social. Y es aquí precisamente donde comienza a perfilarse su impronta adleriana, que no excluía algunas discordancias menores. La psicología social se contrapone a la psicología individual sintética, pues el psiquismo del adulto es una consecuencia tanto de los procesos innatos o congénitos como de la influencia externa, los cuales contribuyen en grados similares a la configuración de cuanto somos como personas. La afirmación del autor es inequívoca: "El hombre individual, en cuanto ser psíquico, aislado, independiente de la sociedad, es una ficción" (Enciso, 1941, p. 39). Tampoco la psique social debería entenderse como la simple sumatoria de las subjetividades 
disponibles, pues tanto la dimensión psicológica subjetiva como la esfera colectiva se determinan e interactúan recíprocamente. Por lo tanto, la condición esencial para la existencia de toda organización es psicológica, al menos en principio, y se explica por las relaciones que mantienen los miembros del grupo unos con otros, y de estos a su vez con el entorno específico. Cuanto se refiera a la psicología del individuo, dirá Enciso sin ambages, habrá de abarcar también a la psicología colectiva.

Los elementos básicos que compendian el pensamiento de Adler son en total diez (Enciso, 1941), aunque su formulación no siempre posea la claridad conceptual deseable. Estos enunciados son muy importantes porque indican la particular recepción que tuvieron los mismos, es decir, los aspectos que Enciso consideró primordiales en la propuesta de Adler, y la lectura que hizo de ellos. (1) La materia viva anhela llegar desde un minus a un plus, y su movimiento se orienta esencialmente al dominio del mundo circundante. (2) El alma es una facultad innata que sintetiza estrategias de ataque o defensa, las cuales aseguran tanto la conservación como el desarrollo del organismo. (3) El alma nunca se encuentra aislada, sino, por el contrario, enlazada a todo cuanto le rodea. (4) En el hombre prevalecen el afán de hacerse valer y la voluntad de dominio. (5) El sentirse un ser inferior contrasta agudamente con el afán de dominación, por lo que el sentimiento de inferioridad emerge como una consecuencia directa. (6) Cualquier tipo de inferioridad que pueda demostrar un individuo en el grupo no depende de lo que este presuntamente oculta, sino de las condiciones sociales que la determinan. (7) La inferioridad necesariamente debe superarse o compensarse, e incluso sobrecompensarse, en función de aspirar hacia el dominio de los demás. (8) La voluntad consiste en una excitación que se transforma desde una sensación de inferioridad o incapacidad hacia otra que representa la capacidad o la plenitud. En otras palabras, la voluntad busca conducir hacia un estado de saciedad. (9) El alma se orienta hacia un objetivo futuro, que es la conservación y la afirmación de la superioridad. (10) Y, de manera conjunta con el afán de predominio, sobresale en el hombre el sentimiento de comunidad.

En la caracterización de Enciso sobre el enfoque adleriano de la personalidad, se asumía que los factores hereditarios no actúan como causas fatalistas e inamovibles de la psique, sino apenas como elementos adicionales que, junto con la crianza, componen la determinación global del comportamiento. Recordaba también la contraposición esencial, ya señalada por el psiquiatra austriaco, entre la voluntad de dominio y el sentimiento de comunidad. Pero, en este aspecto preciso, su intérprete paraguayo encontró la fuente de uno de sus principales desacuerdos. Enciso (1941) destacó que el instinto de poder tiene sus orígenes en la evolución filogenética, y que en las diferentes especies animales, así como en las formas menos desarrolladas de la humanidad, o en los estilos de vida más simples diríamos nosotros, se traduce en conductas elementales y primarias, por completo alejadas de la sofisticación cultural. Estas apuntan, en 
lo esencial, hacia la conservación, el placer o la sexualidad, aunque es necesario hacer la salvedad de que lo placentero y lo doloroso solo sirven como ayudas en la lucha, puesto que el alma se concebía como un órgano para la defensa, conforme a lo afirmado por Enciso (1941), y tal como señaláramos en el párrafo anterior. Donde Freud veía el llanto del lactante y su enfático reclamo del pecho materno, primero como un imperativo de la subsistencia biológica, cuya manifestación más reconocible es el hambre, y luego, en un segundo momento, como un proceder que resulta de la búsqueda de satisfacción de la libido sexual, Adler concebía, sin excluir por ello la necesidad primaria del alimento, una expresión del propósito del niño por ejercer su señorío sobre sectores específicos de su entorno, en este caso concreto, la madre. Enciso (1941) también creía que la finalidad del chupeteo infantil es, primero que nada, la alimentación y el intento por remediar la incapacidad de bastarse a sí mismo, es decir, el impulso básico de conservarse. También coincide con Adler en que, una vez lograda la saciedad, el infante persiste en la ejecución de la misma acción con el fin de lograr su control sobre el mundo exterior, cuya faceta más significativa es, como antes dijimos, la madre.

El llanto del niño es un medio para lograr sus fines, porque si no es capaz de conseguir algo de esa manera, simplemente cambia de estrategia y actúa diferente. En tal sentido, las disimilitudes con Adler son mínimas. Toda expresión de la afectividad es una consecuencia directa del anhelo de supremacía. Entre ellas, también cabe incluir algunos comportamientos como las pataletas, los gritos y el nerviosismo que a veces exhibe el niño. Estas manifestaciones guardan relación con la percepción de inferioridad del hombre. El problema es que las sociedades modernas establecen severas cortapisas para el libre y completo desarrollo de la voluntad. En estas afirmaciones es imposible no ver un eco lejano, aunque con premisas muy modificadas, de las ideas que Freud defendiera en su clásico El malestar en la cultura (Freud, 1981 [1930]), una obra cuyo argumento central subrayó la incomodidad del ello ante las represiones que impone la sociedad para el individuo. Sin embargo, en Adler, la necesidad por la supremacía es una fuerza que compele hacia la superación continua de las limitaciones. Es, pues, un aliciente, un componente positivo en la dirección de la conducta. Como dice Enciso (1941): "Esta enorme rebelión contra la inferioridad es la base de la evolución ascensional de la humanidad" (p. 41). La cultura y la civilización, en su esencia más prístina, son frutos de ella.

Otro aspecto en que las opiniones de Freud y Adler colisionan es en la interpretación de los celos infantiles. Para el primero, la competencia de dos hermanitos por el cariño y las atenciones de la madre es resultado de la lucha por ganar acceso libidinal al objeto de amor. Es el camino que recorre la energía para dirigirse a su destino objetal prioritario. Adler veía las cosas de otra manera. Lo que observó era un combate por la primacía, que no admite la presencia de otros individuos con los que deba compartirse una posesión efectiva sobre la madre. Pero no todo se reduce a este cerrado empeño 
por establecer su potestad en el juego de las relaciones humanas. Cuando el niño ha podido comprobar que su hermano menor es inferior a él, la agresividad inicial decrece, y la disputa se transforma en compasión, afecto y protección. Se trata de una forma de amor asexual, cuyo producto es el sentimiento de comunidad. Esta forma de apego, que identifica cualquier relación del niño hacia la gente, los animales, las plantas y elementos diversos, llega a convertirse en una actitud general, insertándose de hecho en la vida psicológica de la persona (Bitter, 2011). Enciso (1941) pensaba que esta sensibilidad llega a existir no por un antagonismo con la aspiración de dominio, como pensaba Adler, sino como una consecuencia de la misma. Es decir, el hermano mayor encuentra su verdadera justificación psicológica en la existencia del hermano menor. Ambos, pues, se precisan el uno al otro. Resulta interesante lo que Enciso (1941) tiene que decir al respecto:

Es en este punto que nos desviamos bastante de la concepción adleriana, que considera al sentimiento de comunidad como algo distinto y antagónico con el afán de preeminencia. Para nosotros, ese sentimiento de comunidad no es sino una forma evolucionada del mismo instinto de poder, que busca la expansión de la individualidad. (p. 42)

Algunos psicólogos franceses de finales del siglo XIX, como Gabriel Tarde (1843-1904), enfatizaron la importancia radical de la imitación en el proceso de adquisición del comportamiento social (Tarde, 1890). Enciso (1941), que lo menciona explícitamente, consideraba, sin embargo, que los procesos imitativos son más bien un efecto del afán de superioridad. Decía que el niño copia al padre con el anhelo básico de ser poderoso, lo mismo que al hermano mayor. Recurriendo a ejemplos tomados de la vida de sus dos hijos, especula que tanto la imitación como la invención, en las que los niños son pródigos, se originan en el instinto del poder. La prevalencia de la moda es otro ejemplo típico de la tendencia a imitar. La misma lógica siguen el placer y el dolor. Por supuesto, no es posible negar la naturaleza fisiológica de la experiencia dolorosa, pero Enciso opinaba que el niño - que frecuentemente cae, se golpea y llora - lo hace hasta que alguna otra persona, siempre un adulto por supuesto, recrimina a aquel otro que lo empujó, o responsabiliza al elemento físico causante del accidente. En ese momento, el llanto desaparece, pues el predominio deseado sobre el otro ha logrado manifestarse, como producto de la amonestación recibida. Concluye, entonces, que la fuente primordial del placer o el dolor es el ansia de preponderancia. Excusándose por la limitación de tiempo y espacio, que le impedía extenderse más en su explicación, enumera una serie de factores que deberían comprenderse a la luz de la voluntad de dominio y el sentimiento de inferioridad: el dolor moral, las virtudes y los vicios, los crímenes y las perversiones, la envidia, la caridad exhibicionista, la hipocresía y la franqueza, la lealtad y la felonía, la cobardía y el valor, el amor y el odio, las megalomanías, los juegos y los 
deportes, las alegrías, las amarguras, y hasta el suicidio.

Entre las determinaciones que influyen para la formación del individuo y su personalidad, le corresponde un rol preponderante a la sociedad, cuya dimensión psicológica se concibe como una compleja unidad de personas y pequeños núcleos colectivos ligados entre sí (Enciso, 1941). Dentro del contexto social, los impulsos psíquicos adquieren características casi infinitas. Pero tanto desde el punto de vista biológico como del psicológico, los humanos son seres incompletos. Esto nos conduce a una urgencia por llenar nuestras necesidades parciales, impeliéndonos a una aproximación hacia otros individuos, aunque la forma y el objetivo que tomen esos acercamientos pueden ser muy diversos. La familia es uno de ellos, aunque su función no se encuentre enlazada únicamente a la necesidad sexual, de placer o reproductiva. Debido a eso, Enciso (1941) pensaba que la estructura familiar ha variado a lo largo de la historia, estableciendo en cada momento concreto una variedad diferenciada, conforme a las urgencias psicológicas sentidas. Estas se traducen en aspiraciones culturales o valores. En cuanto a las masas, su importancia no se encuentra relacionada con la cantidad de sujetos que la integran, sino con la funcionalidad que adquieren para canalizar las exigencias que impone la voluntad de poder concordante de sus miembros, y cuyo propósito es siempre el dominio del ambiente. Las multitudes que estudió y, a la vez, condenó Le Bon (1895) en sus tratados clásicos eran aquellas surgidas durante la Revolución francesa: mayorías oprimidas por el peso inmenso de la inequidad distributiva, por lo que no cabía esperar de ellas una actitud mínimamente congruente con el sentimiento comunitario, tal como lo entendió Adler. Al contrario, lo que afloraba con facilidad era una reacción contra quienes las sojuzgaban. Por este motivo, Enciso (1941) cuestionó que estas agrupaciones representasen la involución hacia un estado primitivo de la humanidad, como Le Bon (1895) interpretó, sino que eran la muestra palpable de un avance concreto hacia la configuración de una comunidad ideal. Esa clase de solidaridad social, que se descubre en el accionar de tales grupos, está basada en el afán de supremacía y en la sensación de inferioridad de quienes componen las grandes aglomeraciones humanas.

En el contexto de la sociedad ideal a la que alude Enciso, no debe soslayarse el rol fundamental que cumplen los líderes, individuos o grupos de personas dirigentes, ya sea el padre de familia o el jerarca político, salvando las obvias distancias en ambos casos. Ellos poseen la dirección y la sanción social respecto a la actividad que concierne a los integrantes de la agrupación. En términos estrictamente psicológicos, esta condición de dirigencia se identifica con el prestigio. Una vez más, Enciso (1941) repasa la interpretación freudiana del fenómeno, estableciendo que la reputación del líder y la cohesión de la masa que le es correlativa se sustentan en la acción del Eros. Los miembros del grupo se encuentran unidos a sus jefes por 
vínculos libidinosos inconscientes. Esta acción de los impulsos sexuales deposita su fuerza en un objeto preciso y singular, excluyendo así a todos los demás. Pero he aquí que nuestro autor se inclina una vez por la óptica adleriana, pues los afectos son premios e instrumentos (Enciso, 1941) del ubicuo instinto del poder, $y$ se convierten en un canal para superar el sentimiento de inferioridad. Esto equivale a decir que el ungimiento de alguien para asumir el carácter de líder resulta no de un accidente fortuito, sino de la necesidad psicológica de la muchedumbre por obtener un soporte material para sí misma. Quien logra concentrar el arrastre colectivo termina asumiendo por completo esa cualidad.

Como tal, el prestigio es una realidad innegable, por más que dependa de una valoración subjetiva. Por lo tanto, tiene mucho sentido inquirirse respecto a quiénes son los que la obtienen, por qué motivos concretos, y en qué contextos precisos dentro de la actividad normal del grupo. La respuesta de Enciso a estas preguntas era que tal forma de ascendencia la consiguen aquellos que representan o simbolizan las aspiraciones comunes de superioridad de los individuos, considerados separadamente. La pérdida de influencia del caudillo ocurre cuando la masa se siente defraudada por sus acciones, o cuando las condiciones que justificaron el apoyo inicial se han modificado de tal forma que este ya no personifica las ambiciones primigenias del imaginario social, o no ha tenido la habilidad y la sabiduría de evolucionar en paralelo con sus seguidores. La condición de líder, pues, no es absoluta ni eterna, sino circunstancial y relativa a la situación. Una clave de los auténticos liderazgos se encuentra, por consiguiente, en la capacidad de los jerarcas de encarnar el deseo de superación de las inferioridades que posee la multitud. De allí surge su fascinación magnética, que han subrayado tanto Le Bon como Freud. El surgimiento de los dirigentes es producto de la identificación de los anhelos de poderío colectivo con la simbolización del ideal, que el conductor resume en su persona. El sentido que el autor confirió a este problema y, en particular, la conexión de lo social con lo individual queda muy claramente expresado en los párrafos finales de su ensayo:

\begin{abstract}
De todo lo dicho, en que se ha abusado del "sentimiento de comunidad" que suponemos en los lectores, se habría obtenido algún resultado si se ha alcanzado a interesar no sobre nuestra interpretación, sino sobre la trascendente y fructífera concepción de la psicología adleriana, de relevante valor, quizá la aportación más importante de la psicología a la función educadora, que busca un elevamiento espiritual de la humanidad, y que constituye un eficaz instrumento de interpretación de los hechos sociales. (Enciso, 1941, p. 45)
\end{abstract}

\section{CONCLUSIÓN}

El proceso de introducción de las teorías psicológicas en Paraguay no sugiere el desarrollo de una secuencia uniforme, sino que obedece, más bien, a circunstancias disímiles. En algunos casos, la 
transmisión del conocimiento se produjo por intermedio de difusores insospechados, respecto a quienes no se esperarían vinculaciones directas con la investigación de la mente y el comportamiento, al menos en una apariencia superficial. Sin embargo, los análisis centrados sobre la obra de otros pioneros locales en el periodo preuniversitario, como Cecilio Báez (1862-1941), Eusebio Ayala (1875-1942) e Ignacio A. Pane (1880-1920) (García, 2003a, 2005a), permiten distinguir la vigencia de un perfil singular como hombres de acción, a menudo dedicados, si bien no completamente absorbidos, por su vocación política, parlamentaria, ministerial e incluso presidencial. Guillermo Enciso es uno de esos ejemplos y, entre ellos, posiblemente uno de los más prototípicos. Es una muestra del intelectual que navega entre dos aguas, alternando su atención desde la reflexión teórica a la intervención concreta y directa, en este caso, la praxis social. Desde luego que la figura del erudito "puro", divorciado y distanciado de los hechos que condicionan la acción práctica, y que discurre encerrado entre las cuatro paredes asépticas de su estudio en su búsqueda personal del discernimiento y la verdad, se parece mucho más a una ficción ingenua que a la realidad. En Paraguay, pocos de los cultores iniciales de la psicología — si algunose asemejan, aunque sea remotamente, a ese romántico, aunque improbable perfil. Y desde luego, no Guillermo Enciso.

Esta constatación nos dirige a una segunda comprobación, probablemente menos evidente, aunque no menos significativa. Convenimos en que una parte sustancial de los conceptos, teorías e ideas psicológicas, cuya recepción y circulación se produjeron en Paraguay a comienzos del siglo $\mathrm{xx}$, fueron articuladas por hombres con intereses anclados en la esfera pública, en especial la política y los asuntos del gobierno. Esto afecta, a veces de maneras sutiles, los procesos que acompañan la difusión de las teorías científicas en al menos dos aspectos importantes y complementarios: (a) por un lado, la incorporación del respectivo autor asimilado se realiza mediante un énfasis sobre aquellos aspectos, constructos y dimensiones que se insertan de manera preferente o con mayor facilidad en el conjunto de la visión y el sistema de ideas de quien actúa como receptor local, incurriendo en una interpretación que se efectúa a través de las "anteojeras" o referentes teóricos del mismo, es decir, tamizado por las deformaciones conceptuales propias del receptor; (b) por otro lado, la selección que el receptor lleva a cabo en función de los escritos del investigador original se traduce en una elección potencialmente sesgada de los temas y enfoques más directamente relacionados con las predilecciones del receptor, o coincidentes con la agenda teórica o práctica que lo respalda. En este sentido, tratándose de alguien como Enciso, no está fuera de contexto esperar un Adler más "social" que en el caso, por ejemplo, de que su divulgación y comentarios hubieran provenido de un terapeuta psicológico o un psiquiatra, que se identificaría con otras inquietudes o prioridades profesionales más cercanas a las aplicaciones clínicas de la teoría, en 
vez de las derivaciones hacia el ámbito psicosocial o sociológico, habituales en la psicología del individuo.

Lo expuesto no significa que, por fuerza o necesidad, siempre tenga que producirse una falsificación o alteración deliberada de las nociones originales que forman las teorías. Solo establece que los casos de asimilación también son fenómenos instrumentales que responden a objetivos muchas veces implícitos. El Adler asimilado por Enciso no es derivación de una lectura pasiva, acrítica o dogmática. Como ocurre con Freud o Le Bon, igualmente discutidos en el mismo ensayo, fue sometido a una comparación con los puntos de vista del propio Enciso, que, aunque no radicalmente diferentes - especialmente en lo que se refiere a Adler-, aportan matices particulares. Esas disquisiciones conforman la parte más interesante de todo el análisis. Sin embargo, los comentarios a la obra del médico austriaco no dejaron muchas huellas en la psicología paraguaya, al punto, por ejemplo, de constituir el germen para alguna naciente escuela adleriana que pudiera surgir en los años o décadas posteriores. Esto es lo que quiere significar García (2007) cuando apunta a la carencia de tradiciones teóricas sostenidas como una de las características de la psicología paraguaya en el periodo preuniversitario. Aquí observamos el mismo fenómeno: Adler brilló fugazmente en el cerebro de Enciso, pero no dejó secuelas profundas. Su recepción, aunque limitada, es una buena demostración de cómo algunos conceptos de la psicología internacional circularon en el Paraguay de la primera mitad del siglo $\mathrm{xx}$, si bien restringidos a ciertos círculos o referentes intelectuales. Pero lo hicieron, como en ocasiones anteriores se ha dicho (García, 2005b), en su faz teórica y conceptual, no de replicación, ni tampoco de aplicación. En la obra de Enciso, no obstante, queda más por explorar con respecto a sus interpretaciones psicológicas. Constituye un tema obligado para indagaciones futuras, que buscarán desentrañar los indicios, muchos de ellos aún escondidos en textos poco frecuentados o recordados, de una presencia temprana de autores europeos en la psicología paraguaya del siglo $\mathrm{xx}$.

\section{Referencias}

Abramson, Z. (2015). The Meaning of Neurosis According to Adler. The Journal of Individual Psychology, 71(4), 426-439.

Adler, A. (1917a). Study of Organ Inferiority andits Psychical Compensation. AContribution to Clinical Medicine. Nueva York: The Nervous and Mental Disease Publishing Company.

Adler, A. (1917b). The Neurotic Constitution. Outlines of a Comparative Individualistic Psychology and Psychotherapy. Nueva York: Moffat, Yard and Company.

Adler, A. (1930). The Science of Living. Londres: George Allen \& Unwin.

Adler, A. (1947). Conocimiento del hombre. Buenos Aires: Espasa-Calpe.

Adler, A. (1948). El sentido de la vida. Barcelona: Luis Miracle. 
Adler, A. (1953). Práctica y teoría de la psicología del individuo. Buenos Aires: Paidós.

Alarco von Perfall, C. (2015). Alfred Adler. Un precursor de la psicología humanista y su influencia en la psicología positiva. En D. Jáuregui Camasca, R. León Donayre, y M. A. Rodríguez Rea (Eds.), Homenaje a Reynaldo Alarcón (pp. 237-253). Lima: Universidad Ricardo Palma, Editorial Universitaria.

Alexander, R. J., y Parker, E. M. (2009). International Labor Organizations and Organized Labor in Latin America and the Caribbean. Santa Bárbara, CA: ABC-Clio.

Allers, R. (1940). The Successful Error. A Critical Study of Freudian Psychoanalysis. Nueva York: Sheed and Ward.

Angioli, A., y Kruger, P. (2015). A Genealogy of Ideas in Alfred Adler's Psychology. The Journal of Individual Psychology, 71(3), 236-252.

Bernstein, J. (1965). Texto y contexto de El carácter neurótico. En A. Adler, El carácter neurótico (pp. 9-35). Buenos Aires: Paidós.

Bitter, J. R. (2011). Contributions to Adlerian Psychology. Bloomington, IN: Xlibris.

Brett, C. (1997 [1927]). Introduction. En A. Adler, Understanding Life (pp. ixxvii). Oxford: Oneworld.

Buschiazzo, A. (2012). Alfred Adler y la Asociación por el Psicoanálisis Libre (1912-1913). Newsletter del Centro de Estudios Adlerianos, 7, 4-11.
Caeiro, D., y Flecha, V. J. (2001). Crónica de un matrimonio político. La relación histórica entre peronistas y colorados. Asunción: Intercontinental.

Cardozo, R. I. (1927). El psicoanálisis y la educación, o sea, el freudismo como método auxiliar de educación. La Nueva Enseñanza, 1(2), 97-105.

Centurión, C. R. (1961). Historia de la cultura paraguaya (tomo II). Buenos Aires: Biblioteca "Ortiz Guerrero".

Chávez, I. M. (2009). Alfred Adler y Viktor Frankl: el discurso acerca del sentido de la vida. Avances en Psicología, 17(1), 35-58.

Cordón, L. A. (2012). Freud's World: An Encyclopedia of His Life and Times. Santa Bárbara, CA: Greenwood.

Dumont, F. (2010). A History of Personality Psychology. Theory, Science and Research from Hellenism to the TwentyFirst Century. Nueva York: Cambridge University Press.

Enciso, G. (1941). Ensayo de interpretación psicológica de lo social. Revista del Ateneo Paraguayo, 1(2), 35-45.

Escobar Martínez, H. (1978). El presidente Stroessner en el marco de la historia nacional. Asunción: Imprenta Nacional.

Falcone, R. (2007). Condiciones de inicio de la clínica psicoanalítica en Argentina (1930-1942). Anuario de Investigaciones, 14, 135-146.

Freud, S. (1981 [1900]). La interpretación de los sueños. En S. Freud, Obras 
completas (volumen I) (pp. 343-720). Madrid: Biblioteca Nueva.

Freud, S. (1981 [1914]). Historia del movimiento psicoanalítico. En S. Freud, Obras completas (volumen II) (pp. 1895-1930). Madrid: Biblioteca Nueva.

Freud, S. (1981 [1921]). Psicología de las masas y análisis del yo. En S. Freud, Obras completas (volumen III) (pp. 2563-2610). Madrid: Biblioteca Nueva.

Freud, S. (1981 [1924]). Autobiografía. En S. Freud, Obras completas (volumen II) (pp. 2761-2800). Madrid: Biblioteca Nueva.

Freud, S. (1981 [1930]). El malestar en la cultura. En S. Freud, Obras completas (volumen III) (pp. 3017-3067). Madrid: Biblioteca Nueva.

Funder, D. C. (2013). The Personality Puzzle (6. ${ }^{\mathrm{a}}$ ed.). Nueva York: Norton.

Ganz, M. (2001 [1953]). The Psychology of Alfred Adler and the Development of the Child. Abingdon: Routledge.

García, J. E. (2003a). Origens da psicología social no Paraguai. En A. M. Jacó-Vilela, M. Lopes da Rocha y D. Mancebo (Orgs.), Psicologia Social. Relatos na América Latina (pp. 85122). Sâo Paulo: Casa do Psicologo.

García, J. E. (2003b). Ramón Indalecio Cardozo y la difusión inicial de las ideas de Sigmund Freud en el Paraguay. Teoría e Investigación en Psicología, 11(2), 273-318.

García, J. E. (2005a). El joven Eusebio Ayala y la psicología paraguaya. Teoría e Investigación en Psicología, 14, 46-90.
García, J. E. (2005b). Psicología, investigación y ciencia en el Paraguay: características resaltantes en el periodo preuniversitario. Revista Interamericana de Psicología, 39(2), 305-312.

García, J. E. (2007). La psicología en Paraguay y el problema de la determinación de los pioneros. Revista Intercontinental de Psicología y Educación, 9(2), 113-146.

García, J. E. (2011). Historia de la psicología clínica en el Paraguay. Fundamentos en Humanidades, 12(1), 111-147.

García, J. E. (2014). Publicaciones psicológicas en la Revista del Instituto Paraguayo. Universitas Psychologica, 13(5), 1815-1833. Recuperado de http://revistas.javeriana.edu.co/sitio/ psychologica

García-Alandete, J. (2015). La crítica de Rudolf Allers a los fundamentos del psicoanálisis freudiano: axiomas, falacias y principios filosóficos. Revista de Historia de la Psicología, 36(3), 87-110.

González Delvalle, A. (2007). El drama del 47. Documentos de la guerra civil. Asunción: El Lector.

Hergenhahn, B. R., y Henley, T. B. (2013). An Introduction to the History of Psy$\operatorname{chology}$ (7. ${ }^{\mathrm{a}}$ ed.). Boston, MA: Cengage Learning.

Lawson, R. B., Graham, J. E., y Baker, K. M. (2016). A History of Psychology: Globalization, Ideas, and Applications. Nueva York: Routledge.

Le Bon, G. (1895). La psychologie des foules. París: Félix Alcan. 
León, R. (2000). Los psicólogos hispanoparlantes y la teoría de Alfred Adler en la revista Internationale Zeitschrift fuer Individualpsychologie (19141937). Revista Latinoamericana de Psicología, 32(1), 107-126.

León, R., y Zambrano Mora, A. (1992). Honorio Delgado: un pionero de la psicología en América Latina. Revista Latinoamericana de Psicología, 24(3), 401-423.

López, M. (2014). Del "Estado al servicio del hombre libre" al "A balazos o a sablazos, Natalio al palacio": una breve caracterización del pensamiento y el accionar político de Natalicio González. En J. M. Casal y T. L. Whigham (Eds.), Paraguay: Investigaciones de historia social y política (pp. 251-268). Asunción: Tiempo de Historia.

Lück, H. E. (2004). Alfred Adler y la psicología académica. Persona, 7, 11-25.

Méndez Fleytas, E. (1979). Carta a los liberales. Asunción: Artes Gráficas Negri.

Mira y López, E. (1963). Doctrinas psicoanalíticas. Exposición y valoración crítica. Buenos Aires: Kapelusz.

Mora, F. O., y Cooney, J. W. (2009). El Paraguay y Estados Unidos. Asunción: Intercontinental Editora.

Mora Mérida, J. A., y Laza, I. (1986). Alfred Adler, en el marco de la psicología de la motivación. Revista de Historia de la Psicología, 7(4), 55-70.

Obuchowski, K. (1988). Alfred Adler: Precursor of Humanistic Psychology. Individual Psychology, 44(3), 263-269.
Pane, I. A. (1917). Apuntes de sociología. Asunción: España.

Prieto Yegros, L. (1985). El proceso de la dictadura liberal de 1940. Versión documental. Asunción: Cuadernos Republicanos.

República del Paraguay. (1945). Registro Oficial. Asunción: Imprenta Nacional.

Scavone Yegros, R. (2011). Guerra internacional y confrontaciones políticas (1920-1954). En I. Telesca (coord.), Historia del Paraguay (3. ${ }^{a}$ ed.) (pp. 225-264). Asunción: Taurus Historia.

Seiferheld, A. M. (1985). Nazismo y fascismo en el Paraguay. Visperas de la II Guerra Mundial. Gobiernos de Rafael Franco y Félix Paiva (19361939). Asunción: Editorial Histórica.

Stepansky, P. E. (2012). In Freud's Shadow: Adler in Context. Nueva York: Routledge.

Sued, G. (2004). El porvenir de una (des) ilusión. Reflexiones sobre el imaginario psicoanalítico y el discurso teórico-político de Sigmund Freud. San Juan (Puerto Rico): La Grieta.

Tarde, G. (1890). Les lois de l'imitation. Étude sociologique. París: Félix Alcan.

Von Ahn, E. (1996). Dr. Carlos Federico Mora Portillo (1889-1972): pionero de la salud mental y de la psiquiatría en Guatemala. Revista Latinoamericana de Psicología, 28(2), 399-401.

Weckowicz, T. E., y Liebel-Weckowicz, H. P. (1990). A History of Great Ideas in Abnormal Psychology. Ámsterdam: North-Holland. 
